\section{Using Google Maps Web-application to Create Virtual Plant Maps for Use as an Online Study Tool in Plant Identification Courses}

\author{
Matthew S. Wilson ${ }^{1}$ and Chad T. Miller ${ }^{2,3}$
}

ADDITIONAL INDEX WORDs. ornamental horticulture, undergraduate education, laboratory, web-technology

SuMmARY. Virtual plant maps were developed using a web-application for plant identification courses with the goal of providing an additional study resource to students. Each map plots the plants covered for the given weekly plant list, providing photographs of specimens, correct nomenclature, along with additional identification and cultural information. The virtual plant maps provide students an opportunity to review and revisit plants covered in lecture and laboratory sections on their own and at their convenience. An additional advantage of the virtual plant maps is that they can be easily created using a free web-application via any Internet browser, without the need for rigorous understanding of software and webpage design.

$\mathrm{P}$ lant identification courses introduce students to numerous plant species and are a significant component of undergraduate horticulture program curricula. In these courses, students are expected to visually recognize many species based on various plant morphological characteristics and depending on the instructor and/or program curricula are required to provide any combination of the following: plant family, genus, specific epithet, common name, and variety/cultivar. Similar to other horticulture plant identification course formats, the Landscape Plants I and II courses (HORT 374 and HORT 375 , respectively) at Kansas State University (Manhattan) consist of two 50-min lectures and one 2-h laboratory each week. In the lecture component, students are introduced to plants using PowerPoint (Microsoft, Redmond, WA) to highlight plant identification and cultural characteristics. In the laboratory portion, students physically observe the different plants through

Department of Horticulture, Forestry and Recreation Resources, Kansas State University, Manhattan, KS 66506

This manuscript has been assigned Contribution no. 15-227-J from the Kansas Agricultural Experiment Station (KAES)

Mention of a trademark, proprietary product, or vendor does not constitute a guarantee or warranty of the product by the authors, Kansas State University, or the U.S. Department of Agriculture and does not imply its approval to the exclusion of other products or vendors that also may be suitable.

${ }^{1}$ Graduate Teaching Assistant

${ }^{2}$ Assistant Professor

${ }^{3}$ Corresponding author. E-mail: ctmiller@ksu.edu. instructor-guided walks around campus grounds, gardens, arboreta, greenhouses, the neighboring community, etc.

Technological resources provide valuable opportunities and resources for traditional in-class and distance horticulture plant identification courses to supplement lecture and laboratory information. Computer-assisted learning and supplemental online resources have been shown to enhance and increase student learning (Bing, et al., 2012; Schittek, et al., 2001), although Contreras et al. (2013) found little convincing evidence between study methods using some of these technologies and class performance. Various computer-assisted learning resources include extensive web-based plant databases from public institutions (e.g., Missouri Botanical Garden, 2014; Oregon State University, 2014; University of Connecticut, 2014), software databases (Boufford, 1994; Gilman, 1994), dichotomous keys [e.g., FloraGator (Wilson and Flory, 2012)], interactive quizzes (Campbell et al., 2011), and virtual plant walks (Sabota et al., 1995; Wilson and Danielson, 2005).

Moreover, increasingly available mobile technologies, such as smartphones and tablets, increase student access to information and the ability to study and learn anywhere and anytime their schedules allow. As of Jan. 2014 , it is estimated that $83 \%$ of young (18-29 years old) and $74 \%$ of middleaged (30-49 years old) adults in the United States own a smartphone, while $42 \%$ of all U.S. adults own a tablet in
2014, compared with 4\% in 2010 (Pew Research Center, 2014). These mobile technologies use applications (apps), which can supplement traditional paper-based books, notebooks, and notecards to consolidate data and information from various sources into one resource. Increased availability of data via cellular or wireless local area networks (WLAN/Wi-Fi) on college and university campuses coupled with global positioning capabilities of mobile devices allow students to access location-based resources and media for their studies. In 2010, it was estimated that over $80 \%$ of U.S. public and private universities, 4-year colleges, and over $65 \%$ of community colleges have WLAN/Wi-Fi connected classrooms (Green, 2010).

Students in plant identification laboratories often rely on locations of plant materials to relocate reference specimens covered in the course for study purposes. In the Landscape Plants I and II courses at Kansas State University, the authors developed virtual plant walk maps using the Google Maps webapplication (Google, Mountain View, CA) as an additional study tool for students. The virtual plant walk maps provided students with plant specimen locations, plant description data, and visual media. The maps were accessible to all students with data-connected mobile devices or computer access. The objective of this article is to introduce the Google Maps web-application tool and to describe the creation of the maps as a supplemental resource for students.

\section{Creating a virtual plant map with the Google Maps web- application}

Plant walk maps were created using the classic version of Google Maps web-application via an Internet browser. To create custom maps, users are required to have a Google account which is free and available to anyone able to access the web-application via an Internet browser. Using the satellite view (Figs. 1A, B, and 2A) of campus, points on maps were marked or "pinned" according to the plant specimen locations observed in laboratory. For each plant specimen pinned, various data were included. Each mark or "pin" provided a "Title", which consisted of the plant scientific and common name (Fig. 1A). Text in the title 


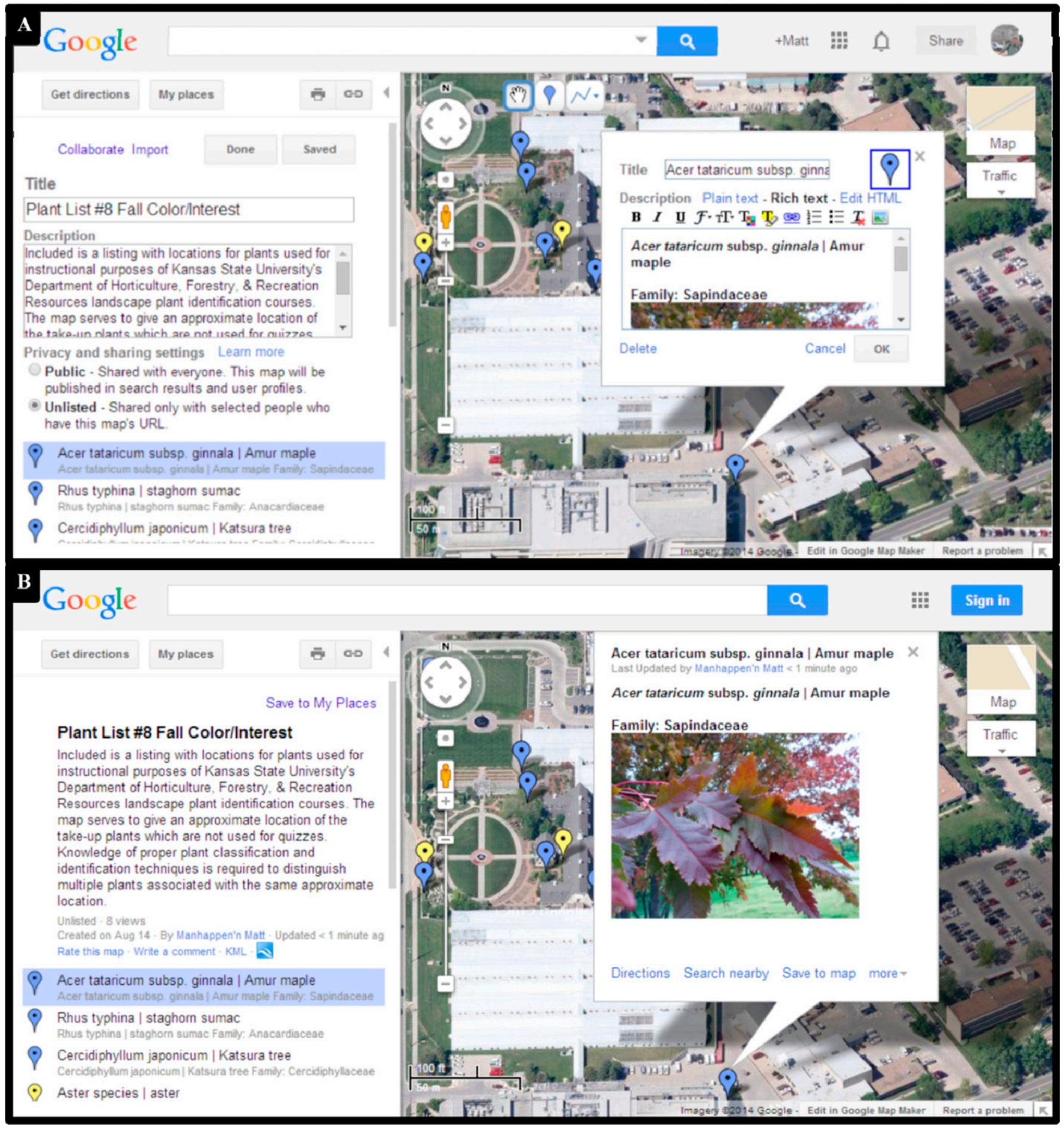

Fig. 1. Individual plant specimen description field with scientific, common and family names, and image media as viewed in editor (A) and view modes (B) of Google Maps web-application (Google, Mountain View, CA) using a computer Internet browser (Imagery Copyright 2014 Google. Google and the Google logo are registered trademarks of Google Inc.).

field was limited to plain text formatting. A "Description" field for each pin allowed for rich text formatting and the proper citation for binomial nomenclature (italic or underline) (Fig. 1A). In the description field, additional relevant information and media were included for each plant including: taxonomic family name, key identification characteristics, important cultivars, unique features, and plant specimen image(s) and video media (Fig. 1B).

Original photographs captured of exact plant specimens observed in laboratory were taken by map collaborators and uploaded to Google+, a social network website with a media storage feature, to obtain the uniform resource locator (URL) necessary to include the images within the description field. All media forms included within the description data field were required to be from websites or social network websites with media storage 


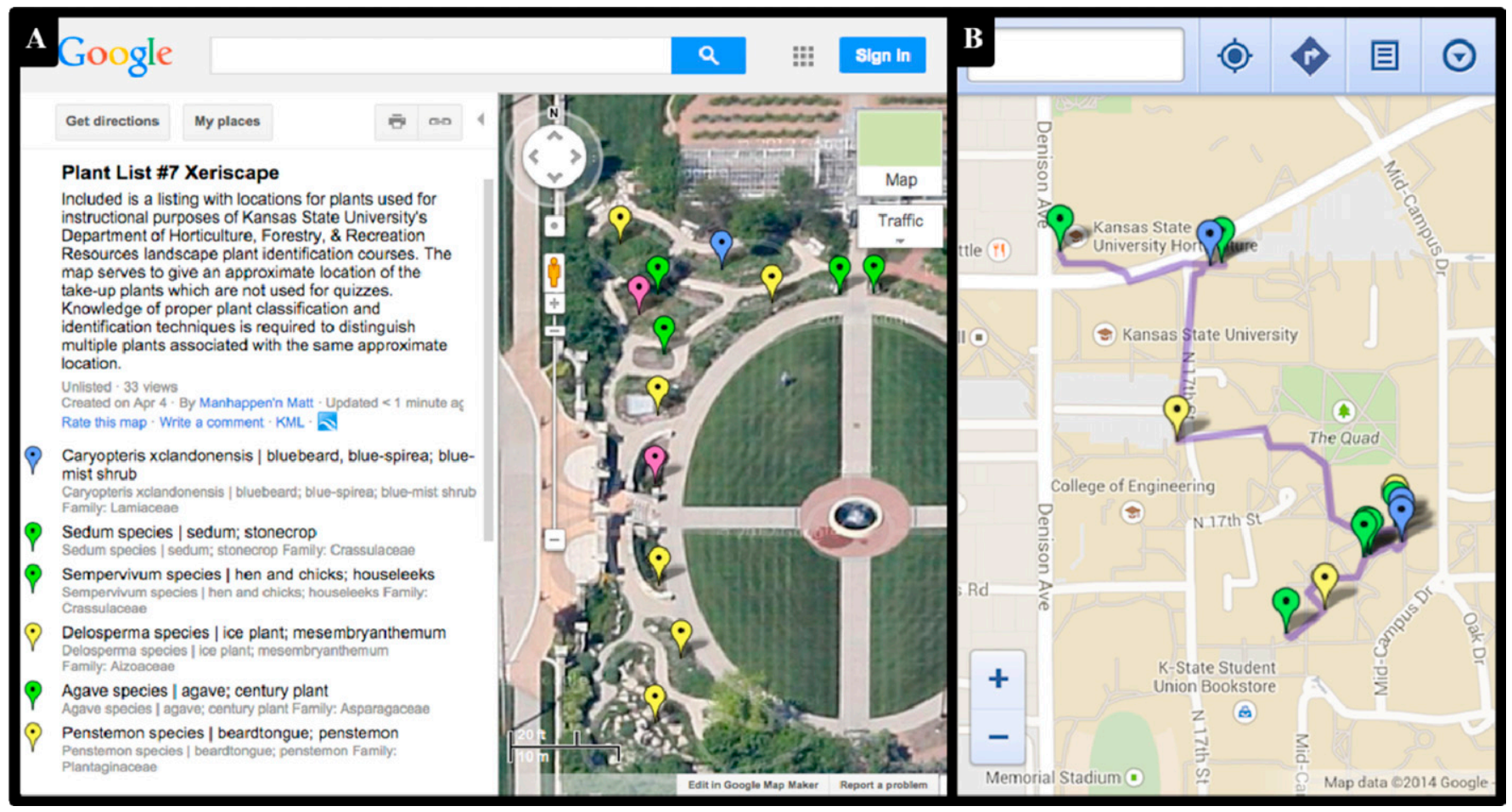

Fig. 2. Plant walk maps as viewed with Google Maps web-application (Google, Mountain View, CA) desktop (A) and mobile (B) Internet browsers. Plant list is shown to the left in A, with the different colored pins in both maps. Panel A also shows a satellite image view, while panel B shows a simple map view with plant pins and an outlined walking route (Imagery Copyright 2014 Google. Google and the Google logo are registered trademarks of Google Inc.).

features, [e.g., Facebook (Facebook, Menlo Park, CA), Flickr (Yahoo!, Sunnyvale, CA), Vimeo (Vimeo, New York, NY), Google+ and YouTube (Google)] that provide a URL associated for each photograph. When images and content not original to the collaborators were used, web addresses and copyright information were cited in the description text. Web videos (e.g., Vimeo, YouTube) were imbedded into the description field using hypertext markup language (HTML) code provided by video host websites' "share/embed" feature and were cited as appropriate.

Individual plant pins were modified by color to represent various plant types included on the plant list (e.g., green $=$ evergreen species, blue $=$ deciduous species, yellow $=$ herbaceous perennial species, and pink = annual species) (Fig. 2A). Plant lists were mapped weekly, according to the walk and plants observed in laboratory. Instructors provided students web-links for individual plant walk maps, which were posted on the course website (K-State Online; Axio Learning, Manhattan, KS). Virtual maps were protected, which allowed students to view the map but restricted their ability to modify the content. Students were provided with a printed plant list in addition to the web-link.

\section{Benefits/challenges of Google Maps virtual plant maps}

There are numerous ways virtual plant walk maps may benefit instructors and students. Instructors may develop "master maps" containing all plants with associated locations to serve as inventories of the plant specimens on or around campus (Polomski and Polomski, 2013). These inventory maps benefit instructors by providing a visual and spatial way to organize plant walks efficiently and effectively. New plant walks can be easily created using the "Save to map" or "Keyhole Markup Language" import features in which plants may be pinned to new maps without recreating individual plant pins or a loss of plant information/locations to the master map (Fig. 1B). Students have an opportunity to benefit by using the maps as a study tool. Students are able to relocate and review, at their convenience, in person or online, the exact plants observed in laboratory along with the following information: family names, identification feature descriptions, and media such as photographs. Additionally, students can review maps numerous times throughout the semester.

The Google Maps web-application is free and accessible through any Internet browser. Maps were accessible on desktop and laptop computers (Fig. 2A), tablets, and smartphone Internet browsers (Fig. 2B). There are advanced versions of the Google Maps web-application available for purchase; however, for the context of the courses discussed herein, the free version was used by the authors and was more than suitable. The web-application is compatible across all operating system platforms, easily accessible, and does not require special or unique software with multiple purchase licenses.

Another major advantage of virtual plant walk maps created using the Google Maps web-application is the ease in which they can be created and viewed. Previously, virtual plant walks required pricey software programs and complex technology skills for image processing and coding of web pages (Sabota et al., 1995; Wilson and Danielson, 2005), whereas the Google Maps web-application is free and user friendly. 
Along with benefits, there are potential challenges in creating and implementing virtual plant walks. While the time to create a map is relatively quick, a challenge for instructors may be the initial time required to pin plants to maps, write identification descriptions, and capture original photographs and video media for plant pins. However, collection of most of the aforementioned items would be required of the instructor for plant identification classes and laboratories regardless of whether the maps are used. As with all technologies, companies release system upgrades, incorporate new features, improve aesthetics, etc., which can be a challenge as well. The maps were developed using the classic version of the Google Maps web-application. A prerelease version, Google Maps beta, is currently available to the public alongside the classic version. Most, if not all features along with all classic maps are to be included and upgraded within the "My Maps" feature of the final release of the Google Maps web-application.

\section{Conclusions}

In conclusion, the Google Maps web-application allows users to create customized virtual plant walk maps as an additional study resource for students enrolled in plant identification courses. The maps can be quickly created using information already prepared for presentation in the classroom. The
Google Maps web-application is a free tool teachers of plant identification can employ to increase students' exposure to the plant materials. As an online resource, the virtual maps provide students an opportunity to revisit plants covered in lecture and laboratory sessions at their convenience.

\section{Literature cited}

Bing, J., S. Pratt-Phillips, and C.E. Farin. 2012. Effect of supplemental online resources on undergraduate animal science laboratory instruction. North Amer. Colleges Teachers Agr. J. 56(1):67-72.

Boufford, R.W. 1994. Using database management software to enhance learning in plant materials courses. Hort Technology 4:185-187.

Campbell, K.R., S.B. Wilson, P.C. Wilson, and Z. He. 2011. Interactive online tools for teaching plant identification. HortTechnology 21:504-508.

Contreras, R.N., J.J. Velez, and R. Golembiewski. 2013. Are learning styles, study habits, and performance correlated in woody plant identification students? HortTechnology 23:130-133.

Gilman, E.F. 1994. Using CD-ROM computer technology to teach plant materials. HortScience 29:461-462 (abstr.).

Green, K.C. 2010. The 2010 national survey of information technology in U.S. higher education. The campus computing project. 22 Oct. 2014. <http://www. campuscomputing.net/sites/www . campuscomputing.net/files/GreenCampusComputing2010.pdf $>$.
Missouri Botanical Garden. 2014. All MO databases. 18 Sept. 2014. <http://www. mobot.org/MOBOT/Research/alldb. shtml>.

Oregon State University. 2014. Landscape plants: Images, identification, and information. 18 Sept. 2014. <http:// oregonstate.edu/dept/ldplants $>$.

Pew Research Center. 2014. Internet project survey. Cell phone and smartphone ownership demographics. 22 Oct. 2014. <http://www.pewinternet.org/datatrend/mobile/cell-phone-and-smartphoneownership-demographics $/>$.

Polomski, B. and T. Polomski. 2013. Share your tree inventory with a simple and inexpensive web-accessible approach. City Trees. Online Mag. Soc. Municipal Arborists 49(6):12-14.

Sabota, C., C.A. Beyl, and G. Ghale. 1995. Developing an integrated location and information database for teaching plant identification and use. HortTechnology 5:178-182.

Schittek, M., N. Mattheos, H.C. Lyon, and R. Attström. 2001. Computer assisted learning. A review. Eur. J. Dent. Educ. 5(3):93-100.

University of Connecticut. 2014. Plant database. 4 Sept. 2014. <http://www. hort.uconn.edu/plants $>$.

Wilson, S.B. and H.E. Danielson. 2005. A new instrument for interactive virtual plant identification and use. HortTechnology 15:729-730.

Wilson, S.B. and L. Flory. 2012. FloraGator: A novel, interactive, and online multiple-entry key for identifying plant families. HortTechnology 22:410-412. 